\title{
DEVELOPING A PEDAGOGICAL MODEL FOR BIOPHILIC DESIGN: AN INTEGRATIVE CONJECTURE MAPPING AND ACTION RESEARCH APPROACH
}

\author{
NIRANJIKA WIJESOORIYA ${ }^{1}$, ARIANNA BRAMBILLA ${ }^{1} \&$ LINA MARKAUSKAITE $^{2}$ \\ ${ }^{1}$ Sydney School of Architecture, Design and Planning, University of Sydney, Australia \\ ${ }^{2}$ Sydney School of Education and Social Work, University of Sydney, Australia
}

\begin{abstract}
Environmentally sustainable design (ESD) was developed as a response to the increasing demands to address sustainability challenges within built environment (BE). BE stakeholders have already adopted ESD as a critical principle in their practices and it is crucial to embed ESD in preparing the next generation of BE professionals. In industry, various ESD frameworks have been developed and adopted to measure the success of design in terms of achieving sustainability. Similar frameworks have been used extensively to guide and scaffold learning for sustainable design in design studios. These frameworks offer predetermined sets of criteria to measure quantifiable building performance parameters. However, there have been growing concerns that the ESD frameworks do not help enhance human-nature connectedness (HNC), where attention was given to biophilic design (BD) to bridge this gap. Availability of few BD frameworks limits the opportunities to adopt them in ESD studios. Further, current BD frameworks focus on qualitative place-making aspects of building designs with less emphasis on quantifiable building performance. This is the critical challenge in teaching BD in ESD studios where the ESD frameworks are used as a central pedagogical tool to guide students' selfassessment, reflection and learning. This chapter reports on an educational design and research study that involved a systematic development of a pedagogical model for incorporating BD in ESD studios. We present here our conceptual and methodological work done as a part of this study consisting two steps. Firstly, we developed a general approach for designing and testing pedagogical innovations in ESD studios by combining educational design-based research and action research approaches. Secondly, we applied this general approach to creating a pedagogical model for teaching students to develop and use BD frameworks. The proposed general approach can be adopted in ESD studios for designing and testing other pedagogical innovations for ESD.
\end{abstract}

Keywords: environmentally sustainable design, biophilic design, architectural design studio, professional education, conjecture mapping, evaluative judgement.

\section{INTRODUCTION}

The impact of buildings on the environment is apparent. The resource utilisation within the building sectors accounts for almost 50\% of energy consumption [1]. With the sustainability agenda emerging to address the rapid depreciation of natural resources, the building sector is challenged to rapidly change as well. One of the main responses from the industry to the environmental crisis has been the emergence of environmentally sustainable design (ESD) [2]. Architectural education also has opened their doors to ESD and learning of ESD practices became common in architectural design studios [3].

These ESD studios differ from the conventional studios with their focus on the sustainability concept and their use of a predetermined set of criteria called "design frameworks" to enhance the sustainability of designs. Among other distinct characteristics, ESD studios: (1) use evidence-based quantifiable design approaches; (2) include a substantial research component; (3) foster transformative learning developing a worldview that embraces the concept of sustainability; and (4) involve students' reflection on achieved outcomes [4]. The design frameworks hold a central position in ESD studios with their ability to impact all other aspects of learning. Majority of ESD studio projects utilise the existing 
green building rating tools from industry in developing design frameworks that are used in studio teaching.

These studios have been incorporating various ESD concepts and methods in teaching, such as energy-efficient design, life cycle analysis, resource consumption and waste management [5]. However, the ESD methods and outcomes have been criticised for their dominant focus on technological solutions and lack of attention to human-nature connectedness [6]. Biophilic design (BD) is a design approach that focuses explicitly on nurturing human-nature connectedness, and there is a growing trend within the industry as well as the green building certification schemes to incorporate BD as a sustainability criterion. Yet, there have been only a handful of BD frameworks developed for assessing biophilic aspects of designs [6]-[8]. Further, the available BD frameworks primarily focus on health, wellbeing and other qualitative aspects of human life. They, in contrast to ESD frameworks, do not account for enhanced building performance. When it comes to teaching BD in ESD studios, lack of BD frameworks that are compatible with ESD objectives is a challenge. There is a need for extensive theoretical and empirical work on how to develop and use BD frameworks in ESD studios productively.

Therefore, we aimed to develop a pedagogical model for teaching BD with a focus on the use of BD frameworks in ESD studios. The development process had two steps. Initially, a general approach was developed for designing and testing pedagogical innovations in ESD studios by integrating action research and conjecture mapping approaches. Subsequently, this general approach was combined with the analysis of challenges that students encounter incorporating $\mathrm{BD}$ aspects in ESD practices, and as a result of this a specific pedagogical model for teaching and learning BD was created. Fig. 1 illustrates these two steps. We explain them in the next section.

\section{A GENERAL APPROACH FOR DESIGNING AND TESTING PEDAGOGICAL INNOVATIONS IN ESD STUDIOS}

Systematic methods are needed for design, development and evaluation of the effectiveness of pedagogical innovations [9]. Such pedagogical innovations fall into the category of educational research by design. Educational research by design includes a range of methods
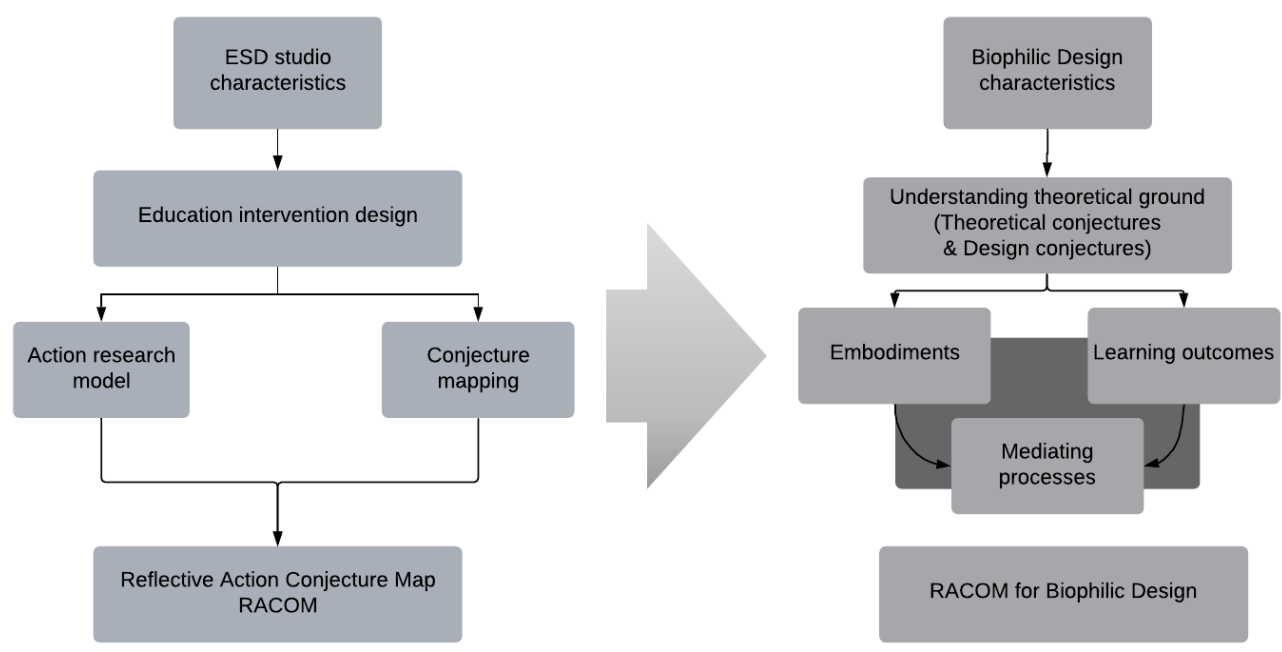

Figure 1: The development process of the pedagogical model for BD. 
widely accepted within the learning sciences, such as educational design research, designbased research, design-based implementation research, and others [10]-[12]. However, these methodologies are not without limitations [13]-[15]. Sandoval [9] points out two specific criticisms for design research in education settings: (1) it "lacks methodological rigour or clear standards"; and (2) such research "fundamentally cannot live up to the claim of simultaneous design evaluation and theory building" (p. 19). In an attempt to overcome these challenges and criticism, Sandoval [9] proposes a systematic approach termed "conjecture mapping" which we used as the key tool to develop and trial our educational innovation. Education in a design studio is unique with its "reflective conversation" with the design problem and action research as the dominant mode of inquiry [16]. In the case of ESD studios - with the complexity of sustainability concepts on top of the conventional design problemsolving - we combined the conjecture mapping and action research to develop an integrated approach. This integrated approach builds on the reflective action research approach by Schon [16] and uses it as a way to enact and understand educational design activity in the studio practices.

\subsection{Action research}

ESD studios are predominantly based on learning by doing, and action research is a key mode of inquiry that helps understand teaching and learning as it unfolds in the educational setting. Action research is associated with other similar educational research approaches, such as "classroom research" [17], "pedagogical action research" [18], "teacher research" [19], and "exploratory teaching and learning" [20]. Even though action research is conceptualised in a number of different ways, there are some shared features. For example, O'Leary [21] describes that action research as follows: it is participatory; it addresses practical problems, it enacts change, it generates knowledge; and it relies on an iterative process. The iterative nature is the critical feature of action research, but different action research approaches suggest different phases in each cycle. For example, Lewin [22] who pioneered action research in his original model had six phases: analysis, fact-finding, conceptualising, planning, implementation of action and evaluation. The reflective model by Schon [16] that is widely used in design disciplines and has four phases: action, planning, observing and reflecting. They are diagrammatically presented and described in Fig. 2.

This simple inquiry model is useful for developing, enacting, evaluating and refining educational innovations in ESD, but much more attention to educational design needs to be included in the inquiry cycle.

\subsection{Conjecture mapping}

Conjecture mapping is a systematic design-based research technique that helps develop a theoretically-informed educational innovation that addresses a specific teaching and learning issue and test it in a natural learning setting. This approach is based on the premise that the design of learning environments intrinsically embodies theoretical hypotheses about how learning happens in some context and how to support it by design [9], [14]. It draws upon both design conjectures and theoretical conjectures.

Sandoval [9] describes the conjecture mapping process as follows: "Whatever the context, learning environment designs begin with some high-level conjecture(s) about how to support the kind of learning we are interested in supporting in that context. That conjecture becomes reified within an embodiment of a specific design. That embodiment is expected to generate certain mediating processes that produce desired outcomes. The ideas a research team has 


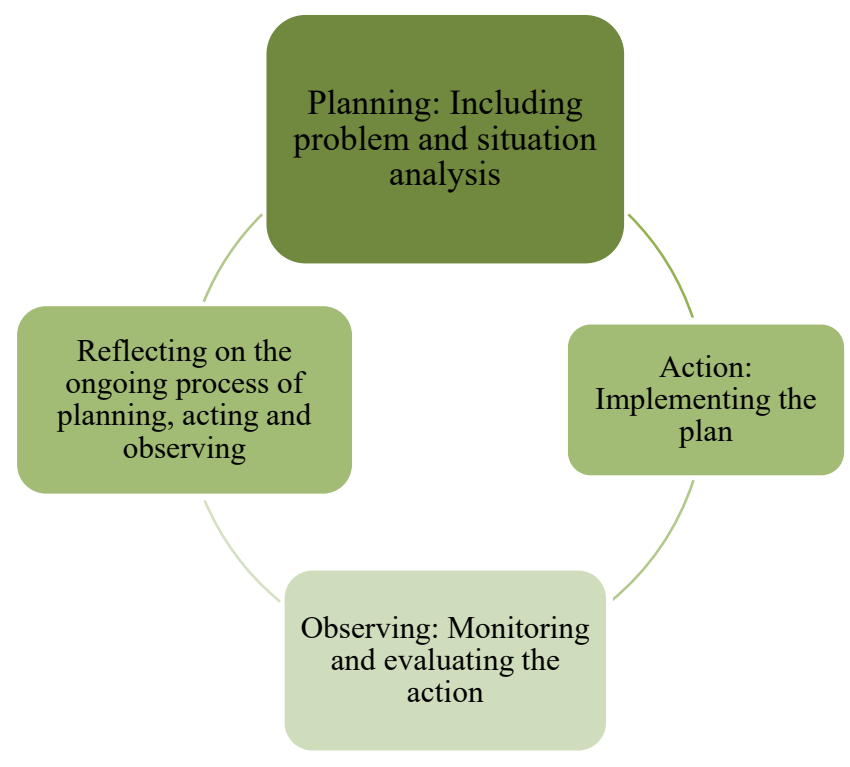

Figure 2: Action research model. (Source: Adapted from [16].)

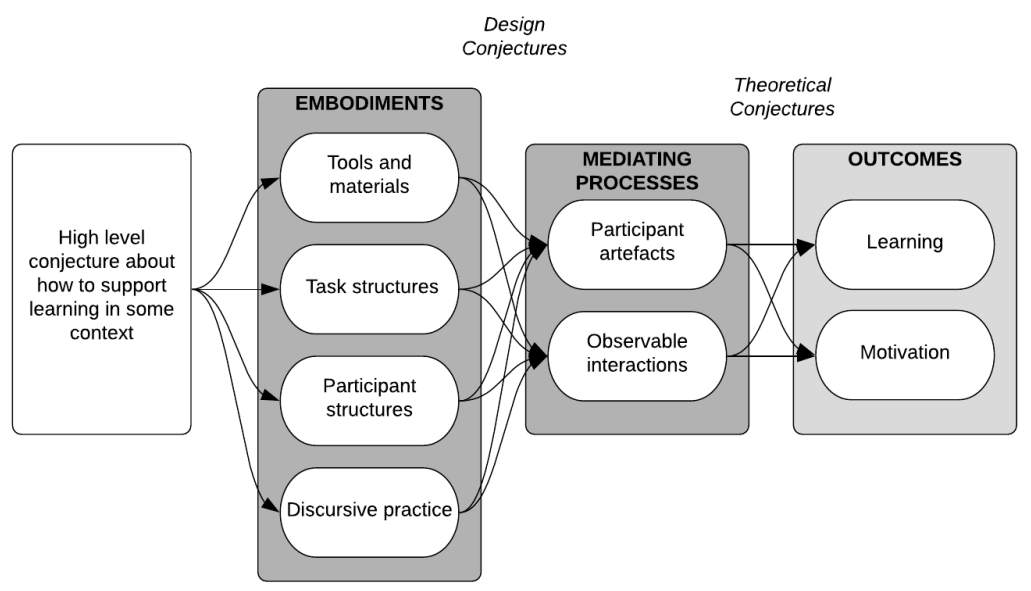

Figure 3: Generalised conjecture map. (Source: Adapted from [9].)

about how embodied elements of the design generate mediating processes can be articulated as design conjectures. The ideas a team has about how those mediating processes produce desired outcomes are theoretical conjectures" (pp. 21-22). Fig. 3 outlines a generalised conjecture map. This mapping helps detail design decisions that underpin an educational innovation in a systematic manner by prompting to articulate the key design elements and how they connect to observable learning processes and outcomes. It helps make the theoretical and design ideas that underpin pedagogical innovations explicit and, therefore, possible to evaluate. 


\subsection{An integrative reflective action and conjecture mapping approach for ESD studio}

The reflective action research cycle by Schon [16] provides a way to show the iterative and ongoing nature of research in developing pedagogical innovations in a design studio. The conjecture map developed by Sandoval [9] complements it by providing a systematic guide to distinctively identify a high-level conjecture, theoretical conjectures, design conjectures, embodiments, mediating processes and learning outcomes. Combining the two schematic presentations of the action research and conjecture map, we developed an integrated model (Fig. 4). It explicitly shows the cyclical nature of pedagogical innovations as well as allows for the details and logic that underpin the iterative design, trialling, evaluation, and refinement of innovations to be represented.

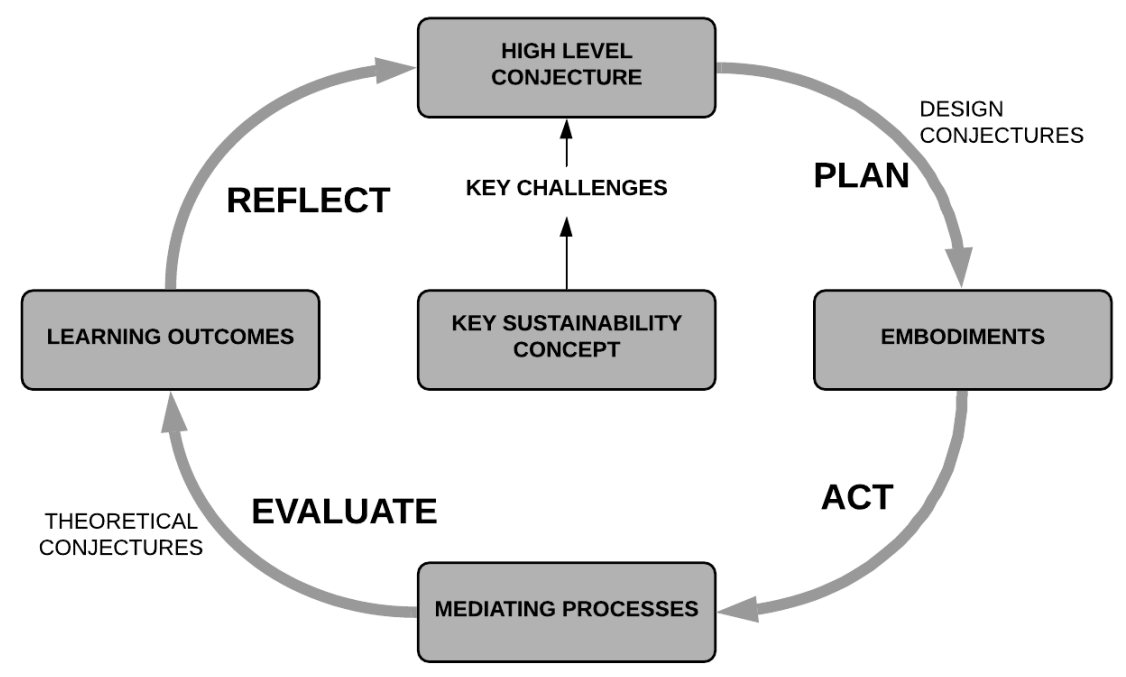

Figure 4: Reflective action conjecture map (RACOM).

The authors in a previous study derived a general educational design framework for ESD studios [4]. It represents the salient features of teaching and learning in ESD studios that we identified through an extensive literature review (Fig. 5).

The themes from this general educational design framework could be used for constructing conjecture maps that are adapted for specific teaching and learning challenges and situations in ESD studios. Key sustainability concepts that underpin teaching and learning and the assumptions made about how this can be supported in ESD studios represent high-level conjectures. Characteristics and key challenges, in Fig. 5, outline the key ideas and themes that usually underpin these assumptions. Theoretical and design conjectures are drawn out of underpinning theories of learning and design practice, where educators should select only the relevant ones. They also could expand this theoretical "toolbox" with other theories of learning and design practice. The key embodiment types, potential student artefacts and typical learning outcomes are also listed in Fig. 5. Embodiments are the educations designs comprising tools, materials, changes in the task and participant structures and the promoted discursive practices to achieve the conjectured learning, used by the educators. Students artefacts are what students are constructing in the mediating processes that are also used to assess the learning outcome. 


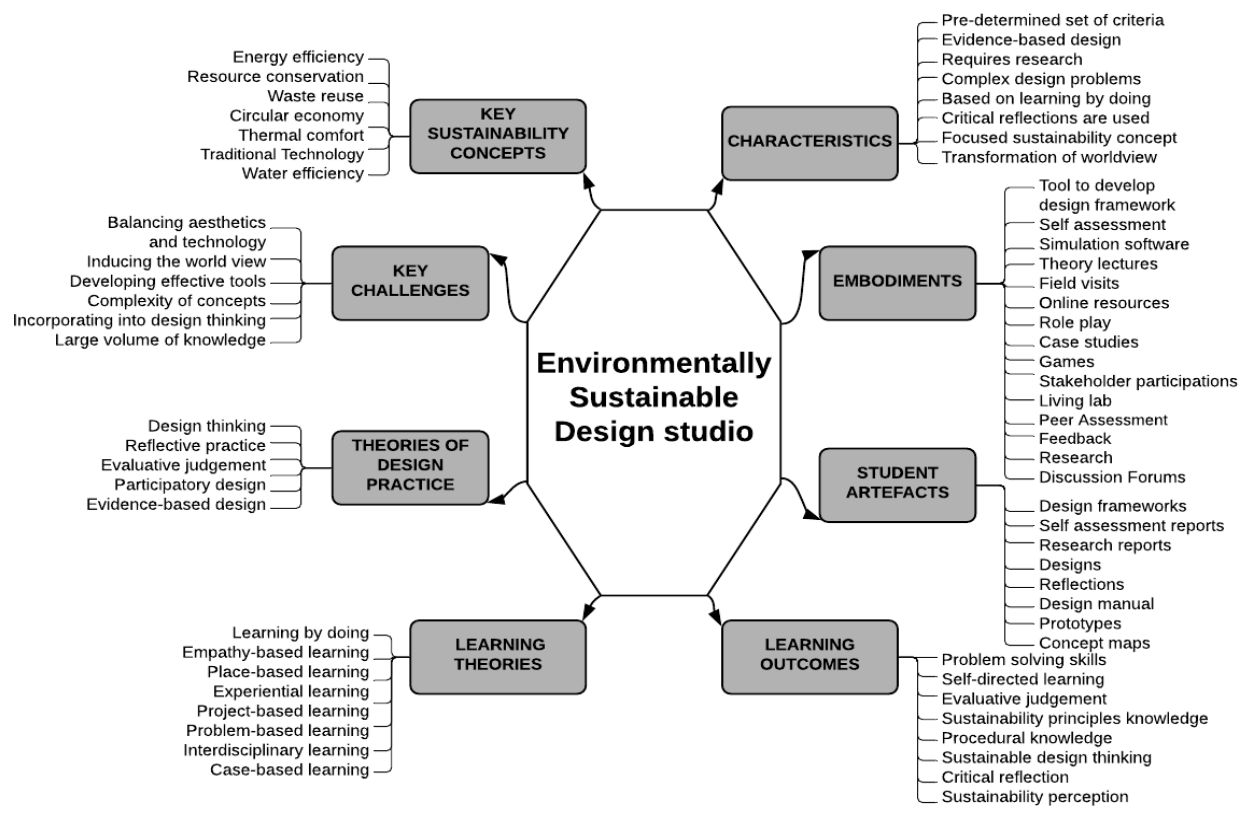

Figure 5: Educational design framework for ESD studio. (Source: Adapted from [4].)

\section{DEVELOPING A REFLECTIVE ACTION CONJECTURE MAP FOR BIOPHILIC DESIGN IN ESD STUDIO}

In our study, to develop a reflective action conjecture map (RACOM) for teaching BD within the ESD studio, we started by identifying the high-level conjecture, key challenges that students encounter learning ESD and BD and how they could be helped to overcome those challenges. After that, we examined the underpinning theories of design practice. They directed us to consider which specific pedagogical design ideas could be adapted for teaching and learning BD, and what would be the primary learning outcomes. Exploring the relationships between the pedagogical design and learning outcomes, we identified the key mediating processes. These processes also pointed out to the artefacts that could be used for evaluation. Based on this systematic process, a conjecture map was developed (Fig. 6). We discuss each component below.

\subsection{High-level conjecture: What to support in teaching BD within ESD}

The high-level conjecture is the key assumption made regarding how to support learning in order to overcome the encountered challenges in a particular teaching and learning context and achieve the desired outcomes. Fig. 5 outlines the key characteristics of teaching and learning in ESD studios. They include: (1) using predetermined sets of criteria to scaffold students' learning; (2) focusing on the provision of evidence for achieving sustainability; (3) engaging students in research for enhancing sustainability; (4) teaching students to deal with complex design problems; (5) involving students in learning by doing; (6) embracing critical reflection; (7) exploring sustainability concept; and (8) transforming students' worldview about design in order to enhance sustainability. We identified that the use of explicit criteria is the most significant characteristic in these ESD studios that make them different from the 


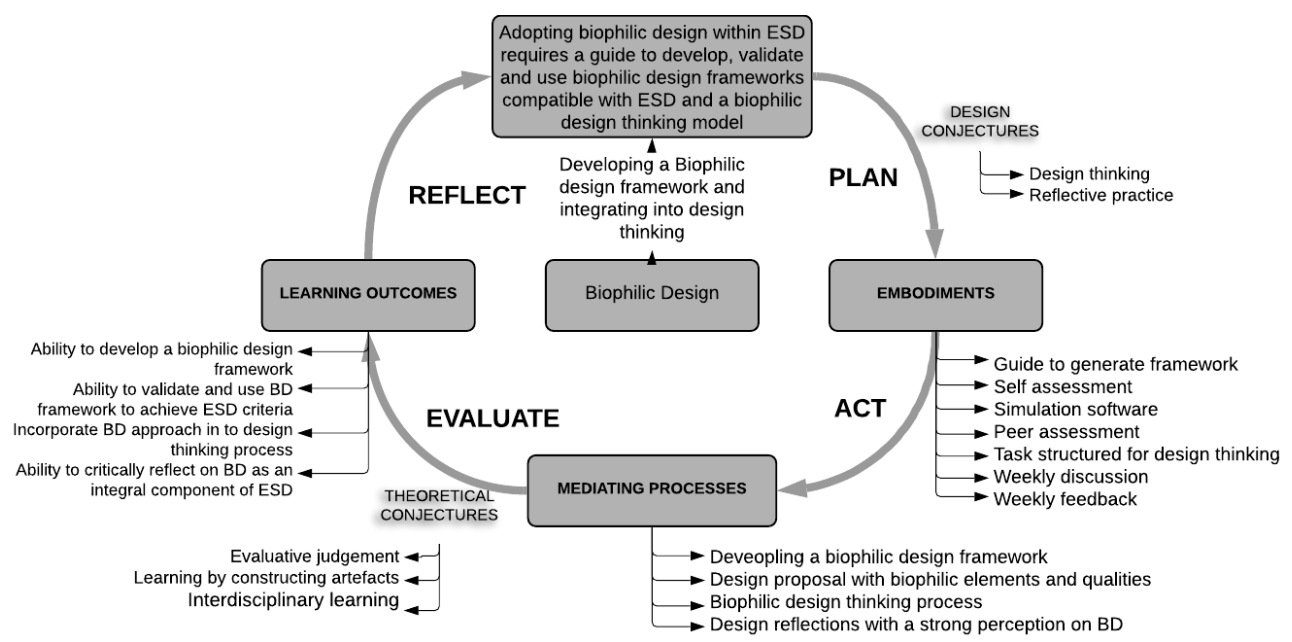

Figure 6: Reflective action conjecture map to teach BD within ESD studio.

conventional design studios. This is consistent with the industry practice of using third party certifications to showcase a commitment to and achievement of sustainability in designs [23]. As Drapella-Hermansdorfer [24] points out, the role of green building certification tools should not be underestimated in ESD. Numerous green building rating tools (GBRTs) available in different shapes and sizes play influential roles in the building industry [25]. Students, therefore, need to be capable to navigate this complexity and make critical judgements about different sets of predetermined criteria and their own work in relation to them.

With the strong focus on evidence in ESD and having to respond to complex design issues that deal with sustainability within a specific context, a guiding framework that helps design a building to suit the intended use and context is critical [23]. Therefore, students need to learn to adapt or develop sets of criteria that are appropriate for specific design problems. A close look into the teaching and learning practices in ESD studios reveals that the GBRTs used in the industry are also commonly used to guide the students to develop their own sets of criteria [2]. However, there is a lack of industry frameworks for BD with only a handful found in the literature [6]-[8].

Further, two different focusses of the typical GBRT and the BD frameworks make the task even more difficult. The former tools mainly focus on technical building performance and resource conservation currently dominating in ESD; the latter frameworks focus on place-making and sensory aspects of design. Careful consideration of the typical criteria in GBRTs and current BD frameworks clearly shows this disparity. GBRTs are focused on highly technical quantifiable criteria, such as energy, water efficiency, resource use, site management and air [26], [27]. In contrast, BD frameworks have highly qualitative criteria, such as the use of natural elements and processes, nature in space and place, direct nature experience, indirect nature experience, evolved human-nature relationship [6]-[8].This indicates that the challenge is not only the disconnection between building performance and place-making but an epistemological gap between the ways in which sustainability and human-nature connectedness are conceived and assessed in architectural practices. 
ESD studios are similar to conventional design studios in terms of being focused around design thinking. However, a typical design thinking model would not suffice the ESD learning process, particularly when BD is in focus, as the development of the ESD framework needs to become a part of the design. This challenges the educators to look for pedagogical models that reflect the complexity of the ESD and allows students to achieve learning objectives in full breadth and depth. In this light, our proposed pedagogical model first focuses on supporting students' learning to develop their own BD frameworks and then focuses on helping students adopt these frameworks in their design thinking processes and practices.

\subsection{Theoretical and design conjectures}

With the requirement to support the development of BD frameworks, the underpinning theoretical ground was explored to identify the critical learning theories and educational design concepts. This enabled us to place our design for teaching $\mathrm{BD}$ in a systematic theoretical context.

Design studio pedagogies are grounded in the theoretical ideas of reflective practice [28]. The design activity within ESD could broadly be described as a reflective response to a design framework. Design frameworks created by students could be understood as design artefacts students create in studio to learn by doing. Understanding the epistemological stances are crucial for design-led pragmatic learning [29] and, when they are created as a part of a formal learning activity, they are also learning and assessment artefacts [30].

A more in-depth look into the design frameworks as learning and assessment artefacts reveals the epistemic nature of the design frameworks and what are the implications for teaching and learning to develop such a framework. Markauskaite and Goodyear [30] point out to three types of assessment artefacts: cultural, conceptual and epistemic. Cultural artefacts are products which are commonly produced and used as a part of daily professional work, such as drawings, designs of building and landscape plans in architecture. Conceptual artefacts are products of deliberative knowledge work aimed at constructing explicit, articulated knowledge for professional practices. Such conceptual artefacts usually can be used beyond one specific problem or setting, such as design patterns or success matrixes in architecture. Epistemic artefacts are artefacts that link conceptual and cultural aspects of professional knowledge to enable a person to tailor professional concepts to the demands of a particular situation. Students' work producing and applying design frameworks for BD involves production of conceptual, cultural and epistemic artefacts simultaneously. Such "ensembles" help students develop flexible professional knowledge [30], [31]. Therefore, students' work developing BD frameworks for their own design work is the central component of our pedagogical model.

Such artefacts also play critical roles in developing students' evaluative judgement, a capability to judge the quality of one's own work [32], [33]. Evaluative judgement is identified as a crucial learning outcome in higher education that helps students become independent of their teachers [34]. Boud [35] has described assessments that involve evaluative judgement as sustainable assessments that meet "the needs of the present and prepares students to meet their own future learning needs" (p. 151). They impact not only students' learning within a particular course but also contribute to their lifelong learning and professional capabilities [36].

In developing evaluative judgement, there are two integral components: understanding the quality and applying standards to own and others work [37]. However, as Tai et al. [34] argue, evaluative judgement is under-theorised and under-researched in higher education and 
suggest five types of pedagogical designs that support evaluative judgement: self-assessment, peer review, feedback, rubrics and exemplars. Students' work constructing and applying design frameworks offer a productive way to support the development of students' evaluative judgement in ESD studios. However, evaluative judgement is contextual and domain-specific [34] where learning in the ESD studios needs to be grounded in an ongoing interaction among the student, teachers, fellow students and industry standards given by GBRTs.

Construction of the frameworks involves interdisciplinary work. This is particularly crucial for BD. For example, the BD guide developed by the Living Future Institute identifies interdisciplinarity as the critical strategy and provides a methodology to develop a BD framework by conducting stakeholder consultations [39]. Supporting interdisciplinary learning within the ESD studio could improve students' capabilities to incorporate multiple perspectives in BD framework criteria.

The last theoretical premise focuses on design thinking. Razzouk and Shute [38] define design thinking as "an analytical and creative process that engages a person in opportunities to experiment, create and prototype models, gather feedback, and redesign" (p. 330). Design ability enables professionals to solve complex and wicked problems [40] including those that are associated with current sustainability agendas. According to Braha and Reich [41], the design process is characterised by being iterative, exploratory, and sometimes a chaotic process. Different models of design thinking have been proposed and used to scaffold design process where there is also a growing realisation that there is a need to develop design thinking approach that suits the complex demands of ESD [42]. From an educational design perspective supporting a thinking process that reflects the complexity of the ESD process by adopting a design framework while embracing the principles of $\mathrm{BD}$ is required.

In developing a pedagogical model around sustainable design thinking the structuring of the tasks and assessments could be the critical success factor. Therefore, embodiments were based on the pedagogical design ideas for supporting evaluative judgement achieved through learning by constructing artefacts and a design thinking model incorporating BD approach.

\subsection{Embodiments}

The generic conjecture map identifies tools and materials, task structures, participant structures and discursive practices as key embodiment types (Fig. 3). The educational design framework for ESD studio lists the common embodiments falling into these categories, such as tools to support framework development, simulation software, lectures, case studies, online resources and field visits to acquire knowledge, activities to understand stakeholder perspectives, research and discussion forums (Fig. 5).

Building on the literature on evaluative judgment, we selected self-assessment, peerreview and feedback as the main pedagogical strategies for helping students develop this skill. The BD framework provides students with a guide for self-assessment embedded in the form of a "success matrix". This matrix provides both the standard and an evaluation system to assess their designs. This usually takes the form of a typical GBRT found in the industry where students develop their own credit awarding criteria for evaluating their designs. Generally, in ESD studios students will use the industry GBRT to derive their success matrix. Since there is lack of industry GBRT with the focus on BD, a systematic tool was created and given to students as a guide to help them develop their BD frameworks. We also provided students with an opportunity to develop their skills in using simulation software to assess how well their designed building achieves the criteria in the success matrix. Students were encouraged to learn these software tools through the weekly lab sessions for energy and life cycle analysis. 
The peer review was integrated into the assessment task to help students develop their evaluative judgement skills. The tasks were structured in line with the design thinking model starting from the development of a success matrix, and then developing a specific design in response to this matrix and systematically exploring and learning different sustainability concepts. Each week students were exposed to a key ESD concept and discussed them in an online discussion forum. Teachers in this forum provided some guiding questions for initiating the conversation and feedback. These weekly sessions also represented expertise from different disciplines that supported students' development of interdisciplinary understanding. Students had to submit their progress weekly prior to the tutorial for feedback. Unlike in the face to face tutorials where the verbal feedback was given, the online forum gave the opportunity to record the feedback on the learning management system.

\subsection{Mediating processes}

The educational design framework for ESD studios lists eight common participant artefacts associated with the mediating processes: sustainability criteria design frameworks, selfassessment reports, research reports, designs, reflections, design manuals, prototypes and concept maps (Fig. 5).

The primary participant artefact and mediating process in our designed pedagogical model for BD is a BD framework which is embedded in the "success matrix" (Fig. 6). This matrix has to be compatible with the ESD and BD standards and include a set of criteria, parameters to identify each criterion and provide quantifiable systematic scheme to evaluate the design against the success matrix. We conjectured that students' work developing and using this matrix would help the students understand standards and systematic methods that can be used to evaluate their designs and simultaneously would contribute to the development of students' evaluative judgement. The design they develop in response to this success matrix will provide us with the next design artefact.

Our suggested pedagogical approach is fundamentally different from the widespread pedagogical approaches in ESD studios that utilise existing GBRTs as success matrixes [24], [43]. In the latter case, GBRTs are provided by teachers and have the role of embodiments rather than participant artefacts. This reduces students' possibilities to take agentic roles in shaping professional standards and ways of knowing [30]. Developing such an agency is an important part of professional learning to solve wicked problems [32], [33].

The portfolio is the major integrative assessment artefact that students produce in the ESD studio. In addition to the matrix, it includes three main participant artefacts and mediating processes: the design, design thinking processes and design reflections. The design of a building is the key artefact in a design studio that synthesises the student design skills. Our conjecture places a strong emphasis on students' weekly discussions and recording of their reflections. We particularly expect that these discussions and reflections will mediate the transformation of students' worldview on the positioning of BD within ESD and subsequent development of their sustainable design thinking. We expect the biophilic design thinking as another mediating process that would be mediated through the critical reflections and demonstrated in their portfolio submissions. Therefore, we need to look at the success matrix and reflective portfolio to determine the achievement of learning outcomes.

\subsection{Learning outcomes}

The educational design framework for ESD studios identifies main learning outcomes such as evaluative judgement, theoretical and procedural knowledge, enhanced design thinking 
models and sustainability perception with the ability to critically reflect (Fig. 5). Our conjecture emphasises four main learning outcomes: ability to develop a BD framework, ability to validate and use it, ability to incorporate $\mathrm{BD}$ in design thinking and ability to reflect on BD as an integral component of ESD (Fig. 6). By achieving these learning outcomes, students would transform their thinking and develop the essential skills required to practice BD within ESD.

The main learning outcome in our conjecture is the student's ability to develop a biophilic design framework. This would be displayed by their success matrix and how far they have adopted BD principles. Once the success matrix is developed, students should develop the skill to validate it and use BD elements to achieve ESD criteria. This learning outcome will be evidenced in students' designs that are an integral component of the validation stage. Incorporation of the $\mathrm{BD}$ into the design thinking process and the ability to critically reflect on $\mathrm{BD}$ are the core parts of students' learning process. The extent to which students were able to develop these skills could be understood from their reflective portfolios.

\section{CONCLUSIONS}

ESD should promote the designs of buildings that enhance human-nature connectedness, and BD is the key strategy for achieving this. However, the research literature on ESD studios, particularly on how to incorporate the BD into the ESD, is limited as compared to the conventional architecture studios. There is a lack of well conceptualised and systematically developed pedagogical models for incorporating BD. This paper outlined our work addressing this gap. First, we described the RACOM approach that we developed to scaffold the systematic development and testing of new pedagogical models for ESD studios. This approach integrates the strengths of the conjecture mapping techniques from educational design-based research [9] with reflective action research that is common in the architectural studios [16]. Therefore, it is both: (1) systematic and well-grounded in learning theories and design-based educational research approaches; and (2) aligned with knowledge practices of teachers in architectural education that now face the need to develop new pedagogical models for incorporating sustainability.

Then, we presented the design of a pedagogical model for teaching BD in ESD studio, showcasing how the RACOM was used as a systematic tool for conceptualising educational research design that we later implemented and tested. The developed general approach could be adopted within the ESD studios to systematically develop and test other pedagogical models for teaching and learning different aspects of ESD. With the growing tendency to integrate more sustainability principles into design studios, we believe, our proposed method could be helpful for educators who want to develop and evaluate their educational innovations for incorporating sustainability systematically.

Developing an educational innovation for ESD studio to teach BD needs to look at and consider both (1) strengths of established ESD practices; and (2) points of deviation that require changing these practices. The use of design frameworks is common in ESD studios and teaching for $\mathrm{BD}$ would ideally incorporate them in the form of BD frameworks. However, the lack of current industry frameworks focused on BD make this task difficult. Further, the situated nature of place-making design practices and qualitative evaluation criteria within the existing BD frameworks further constrain this exercise. Pedagogical models used in these studios thus need to be tweaked to integrate BD meaningfully with the existing ESD frameworks and practices.

Teaching BD poses two challenges of developing, validating and using (1) a compatible BD framework; and (2) a design thinking model to adapt this framework in the studio. Grounding in the theoretical premises of learning by constructing artefacts, evaluative 
judgement and interdisciplinary learning, we designed a pedagogical approach that allows the student to develop their own BD framework embedded into the success matrix. Our key embodiment was a tool to support in developing and validating a BD framework along with simulation software tools, peer assessment, weekly discussion and feedback, structured to support the design thinking process. The study also identified four mediating processes: developing success matrix, design proposal, biophilic design thinking and design reflections. The learning outcomes we conjectured are: the ability to develop a BD design framework, ability to use evaluative judgement to develop and validate ESD in response to the developed BD framework, ability to use the BD framework in the design thinking process, and ability to critically reflect on the biophilic quality of the design outcome as well as the design thinking process.

Future studies could look into developing the RACOM to address other high-level conjectures derived out of ESD studio characteristics, challenges and concepts. The developed generic RACOM, as well as the reflective action conjecture map to teach BD, could become useful tools for scholars in ESD research. They provide a clear guidance on how to conceptualise educational innovations in response to similar education challenges in ESD studios.

\section{ACKNOWLEDGEMENT}

The authors would like to acknowledge the School of Architecture, Design and Planning, University of Sydney higher research by degree funding for the project.

\section{REFERENCES}

[1] Stern, N., Stern Review on the Economics of Climate Change, Cambridge University Press: Cambridge, 2006.

[2] de Gaulmyn, C. \& Dupre, K., Teaching sustainable design in architecture education: Critical review of easy approach for sustainable and environmental design (EASED). Frontiers of Architectural Research, 8(2), pp. 238-260, 2019.

[3] Kayıhan, K.S., Examination of biophilia phenomenon in the context of sustainable architecture. International Sustainable Buildings Symposium, Springer: Cham, pp. 80$101,2017$.

[4] Wijesooriya, N., Brambilla, A. \& Markauskaite, L., 10 questions concerning pedagogical design in environmentally sustainable design studios, 2020.

[5] Altomonte, S., Education for Sustainable Environmental Design: The EDUCATE Project, Summary of Results, EDUCATE Press: Europe, 2012

[6] Kellert, S., Heerwagen, J. \& Mador, M., Biophilic Design: The Theory, Science and Practice of Bringing Buildings to Life, John Wiley: UK, 2008.

[7] Browning, W.D., Ryan, C.O. \& Clancy, J.O., 14 Patterns of Biophilic Design, Terrapin Bright Green: New York, 2014.

[8] Kellert, S. \& Calabrese, E., The Practice of Biophilic Design, Terrapin Bright: New York, 2015.

[9] Sandoval, W., Conjecture mapping: An approach to systematic educational design research. Journal of the Learning Sciences, 23(1), pp. 18-36, 2014.

[10] Barab, S.A. \& Squire, K. (eds), Design-Based Research: Clarifying the Terms, Psychology Press, 2016.

[11] McKenney, S. \& Reeves, T.C., Conducting Educational Design Research, Routledge, 2018. 
[12] Penuel, W.R., Fishman, B.J., Haugan, C.B. \& Sabelli, N., Organizing research and development at the intersection of learning, implementation, and design. Educational Researcher, 40(7), pp. 331-337, 2011.

[13] Anderson, T. \& Shattuck, J., Design-based research: A decade of progress in education research? Educational Researcher, 41(1), pp. 16-25, 2012. DOI: $10.3102 / 0013189 x 11428813$.

[14] Cobb, P., Confrey, J., diSessa, A., Lehrer, R. \& Schauble, L., Design experiments in educational research. Educational Researcher, 32(1), pp. 9-13, 2003.

[15] Edelson, D.C., Design research: What we learn when we engage in design. Journal of the Learning Sciences, 11, pp. 105-121, 2002.

[16] Schon, D.A., The Reflective Practitioner: How Professionals Think in Action, Basic Books: New York, 1983.

[17] Hopkins, E.A., Work-related learning: hearing students' voices. Educational Action Research, 16(2), pp. 209-219, 2008.

[18] Norton, L., Action Research in Teaching and Learning: A Practical Guide to Conducting Pedagogical Research in Universities, Routledge, 2018.

[19] Efron, S.E. \& Ravid, R., Action Research in Education: A Practical Guide, Guilford Publications, 2019.

[20] Allwright, D. \& Bailey, K.M., Focus on the Language Classroom: An Introduction to Classroom Research for Language Teachers, Cambridge University Press: Cambridge, 1991.

[21] O'Leary, Z., The Essential Guide to Doing Research, SAGE: London, 2004.

[22] Lewin, K., Field Theory in Social Sciences: Selected Theoretical Papers, Harpers: Oxford, 1951.

[23] Xue, F., Lau, S.S., Gou, Z., Song, Y. \& Jiang, B., Incorporating biophilia into green building rating tools for promoting health and wellbeing. Environmental Impact Assessment Review, 76, pp. 98-112, 2019.

[24] Drapella-Hermansdorfer, A., The path to sustainability: Architectural education for the future. World Transactions on Engineering and Technology Education, 16(3), 2018.

[25] Illankoon, I.M.C.S., Tam, V.W.Y., Le, K.N. \& Shen, L., Key credit criteria among international green building rating tools. Journal of Cleaner Production, 164, pp. 209220, 2017.

[26] Building Research Establishment, BREEAM International New Construction Technical Manual 2013, Building Research Establishment, 2013. www.breeam.com/discover/technical-standards/newconstruction/.

[27] USGBC, LEED V4 Reference Guide for Building Design and Construction, U.S. Green Building Council: Washington, DC, 2013.

[28] Schön, D.A., Educating the Reflective Practitioner: Toward a New Design for Teaching and Learning in the Professions, Jossey-Bass, San Francisco, 1987.

[29] Bertelsen, O.W., Design artefacts: Towards a design-oriented epistemology. Scandinavian Journal of Information Systems, 12(1), 2002. http://aisel.aisnet.org/sjis/vol12/iss11/12.

[30] Markauskaite, L. \& Goodyear, P., Epistemic Fluency and Professional Education: Innovation, Knowledgeable Action and Actionable Knowledge, Springer: Dordrecht, 2017.

[31] Markauskaite, L. \& Patton, N., Learning for employability in the workplace. Education for Employability, vol. 2, Brill-Sense: Leiden, The Netherlands, 2019. DOI: 10.1163/9789004418707_019. 
[32] Goodyear, P. \& Markauskaite, L., Epistemic resourcefulness and the development of evaluative judgement. Developing Evaluative Judgement in Higher Education: Assessment for Knowing and Producing Quality Work, eds D. Boud, R. Ajjawi, P. Dawson \& J. Tai, Routledge: London, pp. 28-38, 2018.

[33] Goodyear, P. \& Markauskaite, L., The impact of practice on wicked problems and unpredictable futures. Challenging Future Practice Possibilities, eds J. Higgs, S. Cork \& D. Horsfall, Brill-Sense: Rotterdam, The Netherlands, pp. 41-52, 2019.

[34] Tai, J., Ajjawi, R., Boud, D., Dawson, P. \& Panadero, E., Developing evaluative judgement: Enabling students to make decisions about the quality of work. Higher Education, 76(3), pp. 467-481, 2018.

[35] Boud, D., Standards-based assessment for an era of increasing transparency. Scaling Up Assessment for Learning in Higher Education, eds D. Carless, S. Bridges, C. Chan \& R. Glofcheski, Springer: Dordrecht, pp. 19-31, 2017. DOI: 10.1007/978-981-10-3045-1_2.

[36] Boud, D. \& Soler, R., Sustainable assessment revisited. Assessment and Evaluation in Higher Education, 41(3), pp. 400-413, 2016. DOI: 10.1080/02602938.2015.1018133.

[37] Tai, J., Canny, B.J., Haines, T.P. \& Molloy, E.K., The role of peer-assisted learning in building evaluative judgement: opportunities in clinical medical education. Advances in Health Sciences Education, 21(3), p. 659, 2016. DOI: 10.1007/s10459-015-9659-0.

[38] Razzouk, R. \& Shute, V., What is design thinking and why is it important? Review of Educational Research, 82(3), pp. 330-348, 2012.

[39] International Living Future Institute, Biophilic Design Guidebook, International Living Future Institute: Canada, 2018. https://living-future.org.

[40] Roggema, R., Research by design: Proposition for a methodological approach. Urban Science, 1(2), 2016.

[41] Braha, D. \& Reich, Y., Topological structures for modelling engineering design processes. Research in Engineering Design, 14(4), pp. 185-199, 2003.

[42] Berg, A., Stoltenberg, E. \& Reitan, J.B., Sustainable Design Technology: A case Study of a Master Student's Lamp Project, The Design Society, 2014.

[43] Dib, H. \& Adamo-Villani, N., Serious sustainability challenge game to promote teaching and learning of building sustainability. Journal of Computing in Civil Engineering, 28(5), 2014. 